\title{
A PSYCHOLINGUISTIC REVIEW OF THE INTERFACE OF IMPLICIT AND EXPLICIT KNOWLEDGE: THE CASE OF BILINGUAL SPEAKERS USING L2 AS A FOREIGN LANGUAGE
}

\author{
Asim Mohammad \\ Khresheh
}

\author{
Department of Foreign Languages, University of Nizwa, Oman. \\ Email:asim khresheh@yahoo.com
}

(i) Check for updates

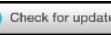

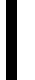

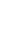
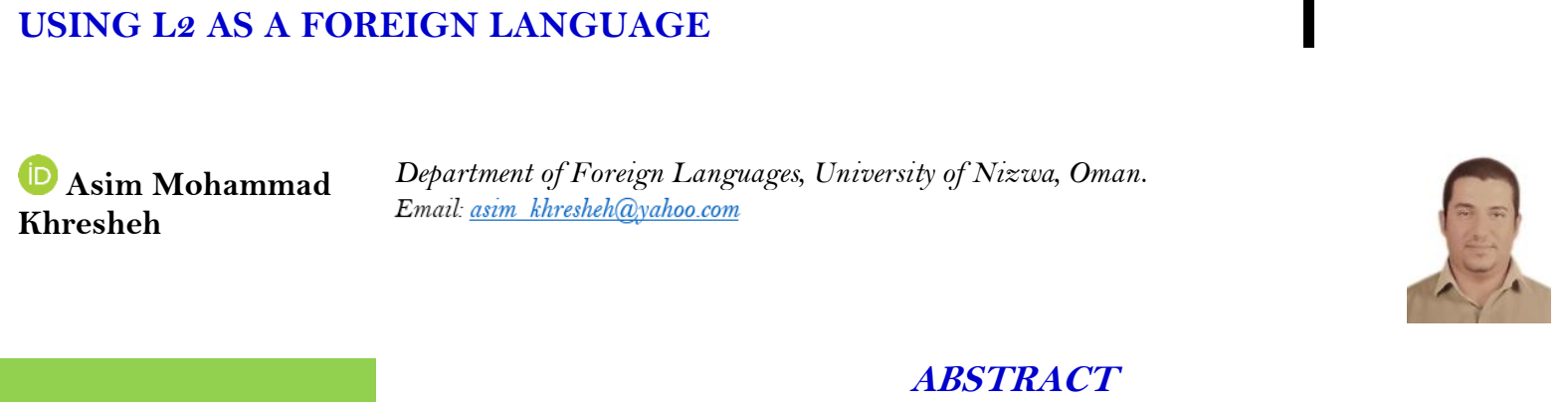

\begin{abstract}
Based on the Literature of SLA that highlights the possible transfer of explicit and conscious knowledge of L2 into implicit, spontaneous and subconscious knowledge, this article reveals, from a psycholinguistic perspective, that any difference in L1 and L2 production in bilinguals' communication is determined by the linguistic knowledge available in the two languages. This study investigates how and when Bilinguals code switch to $\mathrm{L}_{1}$ as the language of identity and expression, and how professional interpreters employ explicitness from L1 into L2 and implicitness from L2 to L1. The findings reveal that L1 is considered more spontaneous than L2 although the latter could be produced fluently and accurately in different communications. This article considers the bilinguals who have their L1 as a mother tongue, but L2 as a foreign language, i.e. learnt later after L1 is acquired. As L2 could be less spontaneous, it means that it is not totally implicit and subconscious as the mother tongue. However, as L2 could be produced fluently and grammatically, it is said to include implicit and explicit/ thinkable knowledge and that the two types of knowledge could interact to exist in L2 production by such users. This conclusion, therefore, advocates the weak interface position of implicit/ explicit knowledge in second language acquisition, i.e. users of L2 could not develop a completely L2 implicit knowledge. Rather, explicit knowledge could exist alongside the procedural/ implicit knowledge in L2 production.
\end{abstract}

Article History

Received: 5 August 2020 Revised: 7 September 2020 Accepted: 30 September 2020 Published: 16 October 2020

\section{Keywords}

Bilingualism

Intuitive knowledge

L2 implicit knowledge

L2 explicit knowledge

Language learning

Linguistic spontaneity

Subconsciousness

Proceduralization

SLA.

Contribution/ Originality: This study is one of the very few studies which have investigated the type of L2 knowledge involved in L2 production by bilingual speakers from a psycholinguistic perspective. It demonstrates that thinkable/ explicit knowledge could exist concurrently with procedural/ implicit knowledge when performing communication in L2 as a foreign language.

\section{INTRODUCTION}

When considering how natural or spontaneous a foreign language flows in language production, it should be investigated while being produced in real communication. This means it should be examined as being produced by fluent users of the L2. This means that language users of L2, rather than its learners, are more successful as interpreters, translators, immigrants, etc. It is important to investigate how L2 helps in different communicative situations.

Psycho-linguistically speaking, if differences or similarities exist when comparing L1 production with that of L2 production in different communicative situations, it could be said that there is a difference or similarity at the 
level of spontaneity. It is rightly observed that empirical studies have still been attempting to reveal more about the complete or partial or impossible conversion of L2 learnt/ declarative knowledge into L2 acquired/ implicit knowledge. Nonetheless, it is of an interest to shed the light on those L2 users who have been using L2 as a foreign language for a long time, say, as interpreters and translators from the source language to the target language and vice versa.

Based on this, this article attempts to shed light on L2 as a foreign/ second language which is learnt at a relatively later age, after the mother tongue is acquired, i.e. when L1 and L2 are not acquired at the same time. This study is concerned with bilinguals whose L1 is their mother tongue, but their L2 is a foreign/ second language.

In fact, L2 learners are much more focused and examined than other language users in SLA research particularly to investigate the interface between implicit and explicit knowledge. Several scholars have been conducting measures as grammaticality judgment tests (Ellis, 1991; Ellis \& Roever, 2018; Maie \& DeKeyser, 2020) to support the existence of the implicit knowledge in L2 learning and how explicit knowledge could be transferred into implicit one. However, other L2 fluent users should not be ignored at the level of investigation. If L2 users' fluency in L2 could be compared with that in L1 in terms of flow, oral responses and code- switching in L1 and L2 based communication, an insight could be revealed regarding the spontaneity in the two languages.

It is of interest to provide an example here to understand how L2 should be viewed and thus recognized, compared with L1 in terms of spontaneity and naturalness. When a fluent English speaker, whose mother tongue is Arabic, got suddenly poked in his flank by his English friend, he produced immediately, in Arabic, the word (Bismillah). This could be translated literally into (in the name of God). His feeling (getting confused because of poking) urged him to express naturally what he felt in his mother tongue rather than English; the language of communication with his friend. The naturalness of the first language is incorporated into the speaker's feelings. Why did he not say immediately in English (Oh my God)? This suggests that the speaker's foreign/second language is not so natural and spontaneous as his mother tongue, although he is fluent in English.

Spontaneity is not only the result of what to produce orally as a result of an action, but also the result of what to do instinctively as an immediate reaction. The Arab man in the previous example put his hand on his flank right away after he got poked and then produced spontaneously the Arabic expression (Bismillah). This series of verbal and non- verbal reactions happen in a very quick sequence. Spontaneity in language production could be the result or the translation of a natural feeling and has to do with language learner as an important related affective variable of his complex structure. The naturally sequential result of this language user did not constitute an L2 production of what he felt. But this means that a feeling triggered the L2 speaker and he showed a higher level of spontaneity towards his L1. That is to say, emotions and feelings are an integral part of any human structure and could not be absent whenever a human engages in any activity from a simple conversation with a family member (informal) to a planned talk (formal) in a conference.

Since the Arabic native speaker produced the Arabic expression due to the affectivity variable, it could be said that his L2 is less spontaneous than his L1. It is true that L1 is his mother tongue whereas L2 is the foreign language. Nevertheless, as far as implicit/ explicit interface of L2 knowledge is concerned, it could be said that his understanding of L2 did not include all L2 knowledge as implicit knowledge. Rather, explicit knowledge existed alongside the implicit knowledge. This is one possibility, however. The other possibilities that could be raised here remain within the weak interface position, i.e. the existence of both implicit and explicit knowledge in the L2 speaker's mind.

On the contrary, if this native Arabic speaker produced an English word or expression as a response to the sudden stimulus, it could be said that his L2 would be spontaneous as much as his L1. There is a consensus, however, that $\mathrm{L}_{1}$ is spontaneous only in language production and this could be used as an indicator of how spontaneous L2 is, as seen in the example given above. If a person's L2 has the same level of spontaneity, it could then be said that his L2 is most likely to contain all or most of L2 knowledge as implicit one. This, indeed, may 
support the interface position as much, if not all, that L2 knowledge exists in the form of implicit knowledge and that it can be produced subconsciously.

There might be other examples or situations, from a psycholinguistic perspective, to consider how L2 flows in production and what affects its flow. For instance, language user might experience stammering or pauses of L2 because he is afraid or angry in some situations. As a result, he could not recall some L2 grammar terms or a lexicon and therefore he may use inappropriate L2 words. He does this to oppose something in the target language and may feel shy to produce L2 because of being worried to commit mispronunciations or grammatical errors. Moreover, if the L2 user is psychologically happy of the target language and has positive attitude towards it, he is likely to master it, but if his attitude is negative, he is unlikely to master it (Gardner (2001).

\section{REVIEW OF L2 SPONTANEITY IN SLA RESEARCH}

Theoretically, Krashen (1981) argued first about the term of spontaneity as a result of acquisition, claiming that, the production of the acquired language is spontaneous, but that of the foreign/learnt language is artificial. He further stated that the affective filter hypothesis for example, indicates self- confidence, anxiety and stress as important emotional variables that affect the process of learning a second/ foreign language. Thus, the lower the anxiety and stress are, the lower the filter is. As a result, the language learner is more likely to be successful provided he receives comprehensible input and gets exposed to the same natural order of knowledge being experienced by first language acquirers.

Practically speaking, if foreign language learner gets no stress and anxiety while being exposed to the target language, the question arises whether this ends up reaching the spontaneity and naturalness of the native speaker's competence. The affective filter hypothesis, along with the other hypotheses incorporated in the Natural approach, does not guarantee that the second/foreign language learner uses the language later as naturally and spontaneously as the native speaker.

Other theories mentioned the importance of affective variables but mentioned nothing about spontaneity. The acculturation model by Schumann (1978), for instance, claims that L2 learners need to get oriented in terms of their feelings and thinking to the culture of the target language in order to learn the foreign language. The psychological and social factors determine how successful the L2 learners are to learn the target language. The social factor has to do with the learner introversion and extroversion, social power, cultural congruence, etc. whereas the psychological factor has to do with cultural shock as a result of being uncomfortable with the target culture, motivation and personal attitude (Schumann., 1990). The same question applies here as far as spontaneity and naturalness of L2 production is concerned. If the L2 learners experience no social or psychological distance with the target language and its culture, again the question arises whether the learners can produce L2 spontaneously at a very later point in their L2 learning. Alternatively, if L2 learners overcome all the challenges resulted from the psychological and social factors and get completely oriented to the target language culture, the question still arises whether they can use the target language as naturally and spontaneously as their mother tongue.

The term spontaneity is viewed based on the interface between implicit/ procedural L2 knowledge and explicit/ declarative knowledge. Ellis (1985) who considered getting involved, by L2 learners in L2 unplanned discourse, ensures some transfer of L2 declarative knowledge into L2 proceduralized knowledge. That is to say, getting to communicate in unplanned discourse means the interaction of L2 declarative and implicit knowledge leading to the development of L2 procedural knowledge and hence acquisition.

Based on many empirical studies, implicit knowledge, as declared by Ellis (2009) is learnable and this means the transferability of explicit knowledge into implicit knowledge through little or no awareness of L2 learners. It is also claimed by Ellis (2009) that explicit knowledge and implicit knowledge are stored separately in the learner's mind, but they could interact to exist together in language production. 
Highlighting the distinction between implicit/ explicit knowledge brings into account the different interface positions of L2 knowledge. Any possible conversion of explicit knowledge into implicit knowledge is referred to as the interface position and this has two forms. The strong form refers to the complete conversion of explicit/declarative knowledge into implicit/ procedural knowledge through practice and the weak interface position refers to the partial conversion of explicit knowledge into implicit Knowledge through L2 learning and instructions. Examples of the interface positions from the prior literature are DeKeyser (2009); Dekeyser (2007); DeKeyser (2003); Ellis and Roever (2018); Ellis (2005); Ellis (2007); Ellis (2011) and Tunney and Shanks (2003).

On the contrary, Scholars like Krashen (1990); Reber and Squire (1998) and Squire (1986); Squire (1987); Squire (1992); Squire(2004) support the non- interface positions claiming that no conversion occurs with L2 learners, implicit knowledge remains automatic in the procedural memory while explicit knowledge remains analyzed and non- automatic in the declarative memory. This distinction though brings a lot of controversy in the form of two different interface positions; however, the transferability and development of L2 implicit knowledge is evident in many empirical studies, Ellis (2005); Macrory and Stone (2000); Hu (2002) and DeKeyser (1995) among others.

On the other hand, the expressions of conscious and subconscious knowledge, as used by Krashen (1981) and Krashen (1990) may be understood in different senses. That is why Schmidt (2001) further explains this difference in 4 categories: "He [Krashen $]$ distinguished consciousness in terms of intentionality (incidental versus intentional learning), attention (i.e. attended versus unattended learning), awareness (implicit versus explicit learning) and control (automatic versus controlled processing)" Ellis (2009). DeKeyser (2009) on the other hand, does not advocate the use of implicit and explicit knowledge to refer to declarative and procedural knowledge, respectively as they may sometimes overlap, but these two pairs (implicit/ explicit) as well as (declarative and procedural) can be used interchangeably in specific contexts. In this respect, Ullman (2007) claims that declarative and procedural distinction exactly mean "the distinction between the mental lexicon on one hand and the rule-governed mental grammar that underlies the composition of complex linguistic forms on another". Paradis (2009) advocates that subconscious knowledge is not entirely procedural and that it is the result of computational and regulatory proceduralization of L2 grammar.

However, what is being considered here, in this article, is the output resulted from the L2 users in the form of L2 verbal production rather than explicit or implicit learning in classroom or the processes that get L2 learners to develop L2 implicit knowledge. This paper investigates, more from a psycholinguistic perspective, to examine how fluent bilingual users, who have L1 as a mother tongue and L2 as a second/foreign language, raises spontaneity of one language compared with the other while being engaged in communicative situations.

This study considers fluent users of L2 claiming that their L2 fluency suggests at least a proceduralization of L2 grammar. If such language users do not have an amount/ a degree of proceduralized knowledge, we could not find them speaking fluently and grammatically in response to many probe questions taking place without prior planning as on T.V or interviews. Ullman (2004) pointed out that "since practice should increase performance in procedural memory, late-language learners should tend to become native like with experience, showing an increased dependence on the grammatical/procedural system" Another good example here is simultaneous interpreter who produces quick and immediate interpretations of the L2 as a second/ foreign language live on air. Khresheh (2018) added that

"it could exist that some fluent non- native speakers of L2 speak chunks of ideas and thoughts continuously in unplanned discourse such as long responses given in unstructured interviewes on T.V or radio and their talk is understood very well. If they have totally implicit knowledge, how have they been able to proceduralize their explicit knowledge? If they have both implicit and explicit knowledge, how could they recall declarative knowledge easily to be gathered with their implicit knowledge? Yes, it is actualization or proceduralization of L2 declarative knowledge of secondary processes into unplanned discourse Khresheh (2018). 
Furthermore, Ellis (2009) used the term 'intuitive' for L2 implicit knowledge to indicate its unconscious production by L2 users, so learners, according to him, could judge if a sentence sounds grammatical or not without being able to state a clear reason behind its un/grammaticality. In this way, the implicit knowledge is intuitive. Supporting this, Ellis (1994) explained that the implicit and explicit knowledge are like a lot of activities happening in human's daily life. Implicit Knowledge is like:

Some things we just come able to do, like walking, recognizing happiness in others, knowing that th is more common than tg in written English, or making simple utterances in our native language. We have little insight into the nature of the processing involved we learn to do them implicitly like swallows learn to fly. Other of our abilities depend on knowing how to do them, like multiplication, playing chess, speaking pig Latin, or using a computer programming language. We learn these abilities explicitly like aircraft designers learn aerodynamics (Ellis, 1994).

Based on this understanding, it is insightful to know how spontaneous and intuitive L2 exists in fluent bilinguals' oral communication. Bilateral interpretation, for example, requires interpreter to orally keep producing quick utterances from L1 to L2 and from L2 to L1. The two languages, in this case, could be compared together as to which directionality L1 or L2 flows smoothly.

\section{SPONTANEITY AND SUBCONSCIOUSNESS OF L2 AS A SECOND/ FOREIGN LANGUAGE}

3.1. Interpretation from $\mathrm{L} 1$ into $\mathrm{L} 2$ and Vice Versa

Simultaneous and consecutive interpreters produce sentences and texts quickly from the foreign language into the source language (their mother tongue) without being aware of the grammar of their mother tongue. However, when interpreting reversibly (from their mother tongue to the foreign language), they are more likely to be aware of the grammar of the foreign language. Their fluency in the foreign language is evident that they produce at least, a certain degree of L2 implicit knowledge. Ellis (2003) points out that "it is perhaps self- evident that all language users, including L2 learners, know rules that guide their performance without any awareness of what the rules consist of. Of course, they can reflect on this implicit knowledge, thus making it explicit".

Having considered this, the notions of 'implicitation and explicitation' should be highlighted here. In translation, implicitation means interpreting an idea or a thought in a way that enables the audience to understand the message implicitly rather than explicitly whereas explicitation refers to the way which interpreters use to make a thought as explicit as possible although it could be inferred and understood without getting it so (Becher, 2011). Explicitation could then include "concretization, division, addition and upgrading) over operations involving implicitation: generalization, contraction, omission and downgrading" (Kinga, 2009). In this regard, Blum-Kulka (1986) states that:

The process of interpretation performed by the translator on the source text might lead to a TL text which is more redundant than the SL text. This redundancy can be expressed by a rise in the level of cohesive explicitness in the TL text. This argument may be stated as «the explicitation hypothesis», which postulates an observed cohesive explicitness from SL to TL texts regardless of the increase traceable to differences between the two linguistic and textual systems involved. It follows that explicitation is viewed here as inherent in the process of translation.

Several studies on interpretation and translation -- Séguinot (1988); Weissbrod (1992); Overås (1998); Hu. and Tao (2009); Tang and Li (2016) and Tang (2018) support the explicitation hypothesis. To sum up, what we are concerned here is how L2 users make their thoughts in L2 clearer than the audience need; although the latter could understand the produced utterances without redundancy. This reveals how it feels to produce interpreters as L2 users.

More importantly, the way explicitation strategy is followed by language users shows a difference between the mother tongue and the foreign/second language in that translators and interpreters believe that their thoughts, produced in an implicit way in their mother tongue, are understood by the native speakers of the same language, 
but they tend to make L2 thoughts as explicit ones to ensure the deliverability and conveyance of the message. These translators and interpreters do not act so from L1 to their L2 and this may imply that they are not certain that their thoughts are understandable if made implicit and thus the linguistic naturalness manifests more here with their L1 than L2..

What is important then is the way language is produced as a result of interpretation or translation from either L1 or L2 and it reveals how bilingual speakers feels towards its consciousness and sub-consciousness. If they make their thoughts as explicit and clear as possible in L2, they engage in consciously cognitive production of the language, but if they produce as implicit and inferred thoughts as possible, they are less likely to consciously think of the language. This actually recalls different cognitive operations when language user's mind gets involved when interpreting or translating in the two different directionalities (from L1 to L2 and from L2 to L1).

Sholl, Sankaranarayanan, and Kroll (1995) mention; "etranslation is conceptually mediated from L1 to L2 but lexically mediated from L2 to L1". This is based on the revised hierarchical model suggested by Kroll and Stewart (1994) namely, "semantic memory principally mediates translation from a bilingual's native first language (L1) to her second language, whereas lexical memory mediates translation from L2 to L1." Getting involved in semantic processing ends bilinguals up to make their thoughts explicit and conscious. They are aware what grammar and semantic relations they should address to convey the meaning. Nevertheless, they are unaware of grammar and semantic processing from L2 to L1 as they are likely to get involved in lexical memory and that is why their thoughts are produced as implicit as possible. If they recognize the grammar and semantic relations in the former case, their thoughts are then conscious but, in the case in which they are unaware of the grammar and semantic processing, their thoughts are likely to be less conscious. This in turn leads to a conclusion which Akan, Karim, and Chowdhury (2019) for instance, arrive at, namely, translating from English into Arabic by native speakers of Arabic is easier than that from Arabic into English.

Bilateral interpretation is another way in which a bilingual speaker of L1 and L2 could reveal if both languages functions in production similarly or differently when provided in either directionality (from the native language to the foreign language and vice versa). By function here, the researcher means speed and not being paused to recall vocabulary and grammar. Any bilateral interpreter, after finishing interpreting from L2 to his native L1 for a participant in the communication, he listens to something in L1 now and needs to shift to his L2 knowledge to follow the directionality from L1 to L2. Does this shift not affect the interpreter's ability to interpret as accurately and fluently as the directionality from L2 to L1? Likewise, when shifting now from L1 to L2 to follow the directionality from L1 to L2, does the interpreter get affected in his linguistic production while providing L2 interpretation? Or is his production as fluent and accurate as L1 interpretation? If no difference is observed between the two directionalities, spontaneity should be viewed as manifesting equally in either directionality. If a difference could be recognized, it could be said that the interpreter's L2 knowledge does not constitute a full- interface position, i.e. he has a degree of implicit and explicit knowledge and this makes the difference.

As an example of bilateral interpretation done on consecutive basis, the United States Courts (2014) published a video for an interpreter interpreting in a court following two directionalities between a defendant and plaintiff. The interpreter interpreted into Spanish fluently, but this is different from her interpretation into English. Her English interpretation is not as fluent as her Spanish interpretation and this is clear in the pauses she made while providing the English interpretation. It could not be said, however, that the interpreter's personal style is to be fluent in one language interpretation but not the other. If it is a speech or personal style, fluency should be observed equally in the two directionalities. It could, then, be said that one language is more spontaneous than the other, so English is used by her in form of implicit/ procedural knowledge along with explicit/ declarative knowledge. Following Ellis (2009) the two types of knowledge could interact together and thus get available in language production of her English and that is why she made pauses in the English interpretation. On the contrary, her Spanish interpretation 
is more spontaneous as she did not pause at all in all turns of this interpretation and as this is different from her English interpretation, it could be said that this interpreter has most if not all Spanish as implicit knowledge.

This might be supported by another interpretation video published by the Interpretation and Translation (2018). In this video, the interpreter who is an Arabic native speaker, keeps moving her eyes up and down while providing interpretation from her L1 to L2 (from Arabic into English). She also makes some pauses along L2 interpretation. In doing so, the interpreter is getting involved to think at least of the words she should recall for appropriate interpretation in L2 and/or she might also be thinking of grammatical rules that fit the ideas being said in Arabic. If she gets more time in each turn of the consecutive interpretation, i.e. waiting a little longer in each turn to get few more utterances produced by the Arabic speaker (the former Iraqi president), she might not need to keep looking up and down thinking of what to produce as the time will be enough for her to produce the interpretation more conveniently and effortlessly, i.e. there will be time to get declarative knowledge ready to produce. Importantly, moving her eyes up and down suggests the existence of declarative knowledge as this has been thinkable through eye movement. Her fluency in L2 could not deny the existence of procedural knowledge though. Supposedly, if she has only declarative knowledge of her competence, she certainly makes grammatical mistakes as this type of knowledge requires sufficient time to think of L2 to get produced correctly.

The interpreters in this example and the previous example produced correct English fluently and grammatically. This is evident that implicit/ procedural knowledge exists in the speakers' minds. Their L2 fluency then involves both the declarative and procedural knowledge, so they get together in their linguistic production. In other words, each interpreter's L2 competence in the two examples contains thinkable/declarative knowledge, alongside fluent procedural knowledge.

\subsection{Bilinguals' Shift (Code-Switching) to L1 in Naturally Communicative Situations}

As far as L2 is concerned as a foreign/ second language, Martin, Altarriba, and Kazanas (2019) studied language dominance of home language and majority language in U.S. In their study of Spanish and English bilinguals, based on the variable of Age of acquisition, they noticed that "predicated English dominant speakers learned English earlier and Spanish later, whereas, predicted Spanish dominant speakers learned English at a relatively older age, and Spanish relatively earlier"(p.206). This difference certainly reveals a tendency to use L1 over L2 in several communicative situations and this could be attributed to the nature of the linguistic thoughts which the bilinguals are likely to use over their counterparts of the foreign/second language. It is almost clear here even though L2 is produced fluently and accurately, say, with the predicated English dominant speakers, knowledge of Spanish as L2 may not be seen as implicit as that of English as L1.

Following the finding of Martin et al. (2019) study, it could happen that a Spanish couple in an English speaking country code-switch to their mother tongue when they are alone at home, but with no doubt could communicate in English when talking with their English colleagues in workplace. Likewise, when they go together to have a break and being alone on the table at restaurant, they would code- switch again to their home language, Spanish. The two languages are not balanced here, as the case with most bilinguals (Tre-ers-Daller \& SilvaCorvalán, 2016) and the bilingual couple code- switch in certain situations to Spanish while being together. Why do not they use L2 all the time? Is it because of being unnatural as their L1? Does their Spanish as a home language cause them to communicate together in Spanish? Does this language have the entire common sense of everything to them as a couple and does it bear all the natural meanings of customs, traditions and culture and that is why they naturally code- switch to it? If yes, accordingly, does this reveal a degree of spontaneity and naturalness of their Spanish as L1 compared with English as L2?

In this example, not communicating in English while being together although it may be proceduralized (used accurately and fluently) suggests a difference between the two languages concerning the degree of spontaneity. The 
same casual conversations performed by them in Spanish while only being together in the kitchen could be easily performed in English if an English-speaking friend is present at such conversations. Haugen (1970) states here:

To be natively competent in two languages would then mean to have had two childhoods, so that all the joys and frustrations of the fundamental period of life could penetrate one's emotional response to the simple words of the language...t would mean to have two different identities, one looking at the world from one point of view, the other from another: it would mean sharing in the social forms, prejudices, and insights of two cultures. In short, it would mean being two entirely different people (Haugen (1970).

As they subconsciously code- switch to their mother tongue, this could reflect more intuitiveness of their L1 more than L2 as the former is a language of identity rather than the latter.

Furthermore, the Gulf countries are rich due to oil production and many expatriates work in such environment. Since Arabic is the mother tongue for its indigenous people, English, to a large long extent, is the lingua-franca (Alharbi, 2017; Alissa, Siemund, \& Leimgruber, 2020; Boyle, 2011). English has also been proven as the language of renaissance and development in the Gulf, and therefore is taught in schools as a foreign language. There are also many native English speakers working in schools and universities. Hence, it is the language that people refer to, in order to understand one another because their first languages are different. Hence, if a nurse and a doctor of two different linguistic backgrounds work together in a hospital in the Gulf region, they use English to communicate. Likewise, if a citizen meets a native English speaker, they are most likely to communicate in English, though pidgin English may be used by the citizen. Most native speakers of English working in the Gulf tend not to use Arabic as they believe English is lingua franca and could be resorted to with different non-English native speakers in different places. Arabic, particularly pidgin Arabic, comes in the second place as a lingua-franca. When communication occurs with no native English speakers, pidgin Arabic is most likely used. It is mostly used by non- native speakers of Arabic when communicating with native Arabic speakers, but not native English speakers.

This is not the case, however, with non- English native speakers. If an Arabic- native speaker meets a nonEnglish native speaker, English is not communicated although it is a lingua-franca. Neither do they employ Pidgin English in their conversation although it could be used to understand each other. Rather, pidgin Arabic is immediately brought into communication. An example here could be a non- native English and non- native Arabic speaker who are to contact with a native Arabic speaker. Although standard or pidgin English could be used by the native speaker of Arabic and be understood by his interlocutor, pidgin Arabic is resorted to by him to communicate with the non- native English and non- native Arabic speaker. Arabic, in this example, is not considered as common as English for communication, i.e. it does not have the total features of lingua-franca as English, yet Arabic is recalled here by Arabic native speakers as the gulf nationals. That is to say, the latter have a natural tendency to use pidgin Arabic than Pidgin English when communicating with non- native English and non- native Arabic speakers.

Importantly, we are not concerned with the non- native Arabic speakers who use pidgin Arabic as they have not developed implicit/ proceduralized knowledge of Arabic. The reason is that they use Arabic as a pidgin rather than a standard language, i.e. they use broken grammar and mix up Arabic words together irrespective of sentence order just to convey their messages. We are actually concerned with the native Arabic speakers who have good command of English while speaking. Although they could use English accurately and fluently, they still prefer to use pidgin Arabic with non-native Arabic speakers, but not non- native speakers of English. The Arabic native speakers here simplify their Arabic as much as possible to convey their messages to their interlocutors, but they do not simplify their English as it is the lingua franca although Pidgin English could easily be understood here. Now the difference, as to which language to simplify, reveals which language is more spontaneous although English as L2 could have a good amount of proceduralized knowledge for many native speakers of Arabic in the Gulf. Based on this, a native Arabic speaker working as an English teacher could use English fluently and accurately in classes and 
meetings, but resorts to use pidgin Arabic, rather than pidgin English with non- native English and non- native Arabic speakers working as cleaners in his workplace.

To support how native speakers, have a natural tendency towards their L1 as the previous case, we could easily imagine which language two native speakers of Portuguese refer to in an English- speaking country when they meet each other for the first time. When they meet by chance in a certain place, their conversation starts in English as the two never met before. When one asks the other: where you are from and they get to know that they are from the same home country and share the same mother tongue, their oral communication naturally shifts to Portuguese although they have talked for some time in English and their flow of communication in English has been very fine as this has directed them to discover their shared mother tongue. Their flow of communication in English, though, continues if they do not share the same mother tongue until they may get friends. In fact, many language users use their L1 although they are living in countries that do not use their home language. For instance, a Pakistani couple uses their Mother tongue when they get together although they use the majority language (English as their L2) in an English-speaking country. They do so with their British friends or with their American colleagues when performing their jobs as conference interpreting. This happens with $\mathrm{L} 1$ acquirers while being together in countries of different language(s). In this regard, Joseph (2004) declares that "what is expressed are the feelings, emotions and passions, usually of an individual, sometimes of an entire ethnicity or gender or other grouping. Linguists and philosophers have mostly shied away from giving serious consideration to expression as a linguistic function". This in turn suggests that natural meanings of objects and the way we think of everything stick to the mother tongue (Slobin, 1986, 1987). This natural tendency reflects a difference in linguistics knowledge between L1 and L2 as spontaneity is raised towards L1 rather than $\mathrm{L} 2$ and. This in turn advocates the existence of purely spontaneous and intuitive knowledge with L1, but not with L2, so L2 is believed here to include both declarative and procedural knowledge in L2 production as L1 is considered the language of feelings within one ethnic group more than L2.

\section{CONCLUSION}

Based on what has been discussed, if L1 and L2 are expected to get produced by bilinguals in different situations and communications as mentioned in this paper, spontaneity of either language could be observed and thus compared with each other. In this way, if spontaneity appears differently in the two languages, one language could be said to be more spontaneous than the other. This in turn concludes which position of implicit/ explicit knowledge to advocate. If $\mathrm{L} 2$, as the case in this article, appears less spontaneous in language production by fluent bilinguals, it means it does not all exist in the form of implicit knowledge. Rather, explicit knowledge exists alongside L2 implicit knowledge and an interaction could happen between them to get L2 to flow grammatically and fluently in language production. In this way, this supports the weak interface position of implicit/procedural knowledge and explicit/ declarative knowledge, i.e. the existence of the two types of L2 knowledge in bilinguals' minds and does not advocate the full- interface position which stresses that L2 could be fully spontaneous and implicit as L1.

Funding: This research article is funded by the University of Nizwa in Oman

Competing Interests: The authors declare that they have no competing interests.

Acknowledgement: All authors contributed equally to the conception and design of the study.

\section{REFERENCES}

Akan, M. F., Karim, M. R., \& Chowdhury, A. M. K. (2019). An analysis of Arabic-English translation: Problems and prospects. Advances in Language and Literary Studies, 1O(1), 58-65. Available at: https://doi.org/10.7575/aiac.alls.v.10n.1 p.58.

Alharbi, N. (2017). English as a lingua franca in the Gulf Cooperation Council states. In Jenkins, J, Baker, W \& Dewey, M (Eds.), The Routledge Handbook of English as a Lingua Franca. Abingdon: Routledge: Routledge Handbooks Online. 
Alissa, A., Siemund, P., \& Leimgruber, J. (2020). Multilingualism and the role of English in the United Arab Emirates. World Englishes: John Wiley \& Sons Ltd.

Becher, V. (2011). Explicitation and implicitation in translation: A corpus- based study of English-German and German- English translations of business texts. PhD Dissertations: University of Hamburg.

Blum-Kulka, S. (1986). Shifts of cohesion and coherence in translation. In J. House and S. Blum-Kulka, Eds., Interlingual and Intercultural Communication (pp. 17-35). Tubingen: Gunter Narr Verlag.

Boyle, R. (2011). Patterns of change in English as a lingua Franca in the UAE. International Journal of Applied Linguistics, 21(2), 143-161.

DeKeyser, R. M. (2009). Cognitive-psychological processes in second language learning. In M. H. Long \& C. J. Doughty (Eds.), The handbook of language teaching (pp. 119-138). Malden, MA: Blackwell.

Dekeyser, R. (2007). Skill acquisition theory. In B. VanPatten \& J. Williams (Eds.), Theories in second language acquisition: An introduction (pp. 97-113). New Jersey: Lawrence Erlbaum Associates, Inc.

DeKeyser, R. M. (2003). Implicit and explicit learning. In C. J. Doughty \& M. H. Long (Eds.), The handbook of second language acquisition (pp. 313-348). Malden, MA: Blackwell.

DeKeyser, R. M. (1995). Learning second language grammar rules: An experiment with a miniature linguistic system. Studies in Second Language Acquisition, $17(3), 379-410$.

Ellis, N. C. (1994). Implicit and explicit processes in language acquisition: An introduction. In N. C. Ellis (Ed.), Implicit and explicit learning of languages (pp. 1-32). San Diego, CA: Academic Press.

Ellis, R. (1991). Grammatically judgments and second language acquisition. Studies in Second Language Acquisition, 13(2), 161186.

Ellis, R., \& Roever, C. (2018). The measurement of implicit and explicit knowledge. The Language Learning Journal, 1-16. Available at: 10.1080/09571736.2018.1504229.

Ellis, R. (1985). Understanding second language acquisition. Oxford: Oxford University Press.

Ellis, R. (2009). Implicit and explicit learning, knowledge and instruction. In R. Ellis, S. Loewen, C. Elder, R. Erlam, J. Philp, \& H. Reinders (Eds.), Implicit and explicit knowledge in second language learning, testing and teaching (pp. 3-25). Bristol: Multilingual Matters.

Ellis, N. C. (2005). At the interface: Dynamic interactions of explicit and implicit language knowledge. Studies in Second Language Acquisition, 27(2), 305-352.

Ellis, N. C. (2007). Implicit and explicit knowledge about language. In J. Cenoz \& N. H. Hornberger (Eds.), Encyclopedia of language and education (Vol. 6, pp. 119-132). New York: Springer.

Ellis, N. C. (2011). Implicit and explicit SLA and their interface. In C. Sanz and R. Leow (Eds.), Implicit andexplicit language learning: Conditions, processes and knowledge in SLA \& Bilingualism. Washington, DC: Georgetown University Press.

Ellis, R. (2003). Second language acquisition. Oxford: Oxford University Press.

Gardner, R. C. (2001). Integrative motivation and second language acquisition. In Z. DÖrnyei and R. Schmdit (Eds) (pp. 1-19). Motivation and Second Language Acquisition (Technical Report \#23) Honolulu: University of Hawai'i. Second Language Teaching and Curriculum Center.

Haugen, E. (1970). On the meaning of bilingual competence. In R. Jakobson \& S. Kawamoto (Eds.), Studies in general and Oriental linguistics: Presented to Shiro Hattori on the occasion of his sixtieth birthday (pp. 221-229). Tokyo: TEC Company, Ltd.

Hu, G. (2002). Psychological constraints on the utility of metalinguistic knowledge in second language production. Studies in Second Language Acquisition, 24(3), 347-386.

Hu, K.-B., \& Tao, Q. (2009). Explicitation in the Chinese-English conference interpreting and its motivation. A study based on parallel corpus. Journal of PLA University of Foreign Languages, 32(4), 67-73.

Interpretation and Translation. (2018). Arabic English consecutive interpretation. Retrieved From: https://www.youtube.com/watch?v=Qor1wvzLMoY. 
Joseph, J. E. (2004). Linguistic identity and the functions and evolution of language. In: Language and Identity. London: Palgrave Macmillan.

Khresheh, A. (2018). How Can L2 lexicon be proceduralized while interacting with proceduralized L2 grammar: A cognitively linguistic model of the declarative/procedural interface. Journal of Advances in Linguistics, 9, 1443-1451.

Kinga, K. (2009). The asymmetry hypothesis in translation research. In: Dimitriu, R., Shlesinger, M. (Eds.), Translators and Their Readers. In Homage to Eugene A. Nida (pp. 283-303). Brussels: Lés Éditions du Hazard.

Krashen, S. D. (1981). Second language acquisition and second language learning. Oxford: Pergamon.

Krashen, S. (1990). How reading and writing make you smarter, or, how smart people read and write. Georgetown University Round Table on Languages and Linguistics (pp. 364-376). Washington, D.C: Georgetown University Press.

Kroll, J. F., \& Stewart, E. (1994). Category interference in translation and picture naming: Evidence for asymmetric connections between bilingual memory representations. Journal of Memory and Language, 33(2), 149-174.

Macrory, G., \& Stone, V. (2000). Pupil progress in the acquisition of the perfect tense in French: The relationship between knowledge and use. Language Teaching Research, 4(1), 55-82. Available at: https://doi.org/10.1191/136216800669518189.

Maie, R., \& DeKeyser, R. M. (2020). Conflicting evidence of explicit and implicit knowledge from objective and subjective measures. Studies in Second Language Acquisition, 42(2), 359-382. Available at: https://doi.org/10.1017/s0272263119000615.

Martin, J., Altarriba, J., \& Kazanas, S. (2019). Is it possible to predict which bilingual speakers have switched language dominance? A discriminant analysis. Journal of Multilingual and Multicultural Development, 41(3), 206-2 18.

Overås, L. (1998). In search of the third code: An investigation of norms in literary translation. Meta: Translators' Journal, 43(4), 557-570.

Paradis, M. (2009). Declarative and procedural determinants of second languages. Amsterdam: John Benjamins.

Reber, P. J., \& Squire, L. R. (1998). Encapsulation of implicit and explicit memory in sequence learning. Journal of Cognitive Neuroscience, $10(2)$, 248-263. Available at: https://doi.org/10.1162/089892998562681.

Schmidt, R. (2001). Attention. In P. Robinson (Ed.), Cognition and second language instruction (pp. 3-30). Cambridge: Cambridge University Press.

Schumann, J. (1978). The pidginization process: A model for second language acquisition (pp. 367-379). Rowley: Newbury House Publishers.

Schumann, J. H. (1990). Extending the scope of the acculturation/pidginization model to include cognition. Tesol Quarterly, 24(4), 667-684. Available at: https://doi.org/10.2307/3587114.

Séguinot, C. (1988). Pragmatics and explicitation hypothesis. Translation, Terminology, Redaction, 1(2), 106-114.

Sholl, A., Sankaranarayanan, A., \& Kroll, J. F. (1995). Transfer between picture naming and translation: A test of asymmetries in bilingual memory. Psychological Science, 6(1), 45-49. Available at: https://doi.org/10.1111/j.1467-9280.1995.tbo0303.x.

Slobin, D. (1986). The development from child speaker to native speaker. Paper presented at the First Annual Symposium on Culture and Human Development. University of Chicago.

Slobin, D. (1987). Thinking for speaking. Paper presented at the Proceedings of the Thirteenth Annual Meeting of the Berkeley Linguistics Society.

Squire, L. R. (1986). Mechanisms of memory. Science, 232(4758), 1612-1619.

Squire, L. R. (1987). Memory and brain. New York: Oxford University Press.

Squire, L. R. (1992). Memory and the hippocampus: A synthesis from findings with rats, monkeys, and humans. Psychological Review, 99(3), 195-231. Available at: https://doi.org/10.1037/0033-295x.99.3.582.

Squire, L. R. (2004). Memory systems of the brain: A brief history and current perspective. Neurobiology of Learning and Memory, 82(3), 171-177. Available at: https://doi.org/10.1016/j.nlm.2004.06.005.

Tang, F., \& Li, D. (2016). Explicitation patterns in English-Chinese consecutive interpreting: Differences between professional and trainee interpreters. Perspectives, 24(2), 235-255. 
Tang, F. (2018). Explicitation in consecutive interpreting. Amsterdam/Philadelphia: John Benjamins Publishing Company.

Tre-ers-Daller, J., \& Silva-Corvalán, C. (2016). Digging into dominance: A closer look at language dominance in bilinguals.In Language Dominance in Bilinguals: Issues of Measurement and Operationalization. Edited by Carmen Silva-Corvalán and Jeanine Tre-ers-Daller (pp. 1-14). Cambridge, UK: Cambridge University Press.

Tunney, R. J., \& Shanks, D. R. (2003). Subjective measures of awareness and implicit cognition. Memory \& Cognition, 31(7), 10601071. Available at: https://doi.org/10.3758/bfo3 196127.

Ullman, M. T. (2007). The biocognition of the mental lexicon. In M. G. Gaskell (Ed.), The Oxford Handbook of Psycholinguistics (pp. 267-286). Oxford: Oxford University Press.

Ullman, M. T. (2004). Contributions of memory circuits to language: The declarative/procedural model. Cognition, 92(1-2), 231270. Available at: https://doi.org/10.1016/j.cognition.2003.10.008.

United States Courts. (2014). Example of consecutive interpreting. Retrieved from: https://www.youtube.com/watch?v=tFsKulFcauY.

Weissbrod, R. (1992). Explicitation in translations of prose-fictions from English to hebrew as a function of norms. MultilingualJournal of Cross-Cultural and Interlanguage Communication, 11(2), 153-171. Available at: https://doi.org/10.1515/mult.1992.11.2.153. 